\title{
Effect of Thermal Cyclic Loading on Stress-Strain Response and Fatigue Life of 3D Chip Stacking Structure
}

Liang Zhang ( $\nabla$ zhangliang@jsnu.edu.cn )

Jiangsu Normal University

Su-juan Zhong

Zhengzhou Research Institution

\section{Original Article}

Keywords: 3D IC, Taguchi method, control factors, fatigue life

Posted Date: July 22nd, 2020

DOI: https://doi.org/10.21203/rs.3.rs-46874/v1

License: (c) (1) This work is licensed under a Creative Commons Attribution 4.0 International License.

Read Full License

Version of Record: A version of this preprint was published at Chinese Journal of Mechanical Engineering on November 27th, 2021. See the published version at https://doi.org/10.1186/s10033-021-00640-w. 


\title{
Effect of thermal cyclic loading on stress-strain response and fatigue life of 3D chip stacking structure
}

\author{
Liang Zhang ${ }^{1,2}$, Su-juan Zhong $^{1}$ \\ 1. Zhengzhou Research Institute of Mechanical Engineering Co., LTD, Zhengzhou 450001, China; \\ 2. School of Mechatronic Engineering, Jiangsu Normal University, Xuzhou 221116. \\ Corresponding author: Liang Zhang, Email: zhangliang@jsnu.edu.cn, Tel: 0516-83500260, Fax: 0516-83500260
}

Corresponding author: Liang Zhang, Email: zhangliang@jsnu.edu.cn, Tel: 0516-83500260, Fax: 0516-83500260

Abstract In this paper, the thermo-mechanical reliability of IMCs $\left(\mathrm{Ni}_{3} \mathrm{Sn}_{4}, \mathrm{Cu}_{3} \mathrm{Sn}, \mathrm{Cu}_{6} \mathrm{Sn}_{5}\right)$ solder joints and $\mathrm{Sn}-3.9 \mathrm{Ag}-0.6 \mathrm{Cu}$ solder joints were investigated systematically in $3 \mathrm{D}$ chip stacking structure subjected to an accelerated thermal cyclic loading based on finite element simulation and Taguchi method. Effects of different control factors, including high temperature, low temperature, dwell time of thermal cyclic loading, and different IMCs on the stress-strain response and fatigue life of solder joints were calculated respectively. The results indicate that maximum stress-strain can be found in the second solder joint on the diagonal of IMC solder joints array, for $\mathrm{Sn}-3.9 \mathrm{Ag}-0.6 \mathrm{Cu}$ solder joints array the corner solder joints shows the obvious maximum stress-strain, these areas are the crack propagated locations. The stress-strain and fatigue life of solder joints is more sensitive to dwell temperature, especially to high temperature, increasing the high temperature, dwell time, or decreasing the low temperature, can reduce the stress-strain and enlarge the fatigue life of solder joints. The optimal design in the 3D IC structure has the combination of the $\mathrm{Cu}_{6} \mathrm{Sn}_{5} / \mathrm{Cu}_{3} \mathrm{Sn}, 373 \mathrm{~K}$ high temperature, $233 \mathrm{~K}$ low temperature, and 10min dwell time.

Key words 3D IC, Taguchi method, control factors, fatigue life

\section{Introduction}

With the development of chip technology, the use of Moore's law in microelectronic industry may approach the limit, three-dimensional integrated circuits (3D-IC) technology can overcome the limitations of the Moore's law with the advantage of high density integration, high performance and low power consumption ${ }^{[1-3]}$. Therefore, the chip stacking in 3D IC has attracted considerable attention in electronic industry, different bonding technology have been developed to ensure the chip (or wafer) vertical stacking, among the bonding technology, TLP bonding with solder has been proposed as an effective method to implement low temperature bonding and high temperature service.

Talebanpour ${ }^{[4]}$ used $\mathrm{Sn} 3.0 \mathrm{Ag} 0.5 \mathrm{Cu}$ as interconnection materials in $3 \mathrm{D}$ structure with $260^{\circ} \mathrm{C}$ reflow temperature and aging to obtain total $\mathrm{IMC}\left(\mathrm{Cu}_{6} \mathrm{Sn}_{5} / \mathrm{Cu}_{3} \mathrm{Sn}\right)$. $\mathrm{Chu}^{[5]}$ investigated $\mathrm{Cu} / \mathrm{Sn} / \mathrm{Cu}$ and $\mathrm{Ni} / \mathrm{Sn} / \mathrm{Ni}$ solder joints for low temperature stable transient liquid phase (TLP) bonding, $\mathrm{Cu}_{6} \mathrm{Sn}_{5}, \mathrm{Cu}_{3} \mathrm{Sn}_{,} \mathrm{Ni}_{3} \mathrm{Sn}_{4}, \mathrm{Ni}_{3} \mathrm{Sn}_{2}$ can be detected respectively. Chen ${ }^{[6]}$ investigated the $\mathrm{Cu} / \mathrm{Sn} 3.5 \mathrm{Ag} / \mathrm{Cu}$ and $\mathrm{Cu} / \mathrm{Sn} 3.5 \mathrm{Ag} / \mathrm{Cu} 15 \mathrm{Zn}$ based on TLP bonding, $\mathrm{Cu}_{6} \mathrm{Sn}_{5}$ and $\mathrm{Cu}_{6}(\mathrm{Sn}, \mathrm{Zn})_{5}$ were found in the solder joints, it is found that the $\mathrm{Cu}_{6} \mathrm{Sn}_{5}$ can weaken the bond reliability resulting from its homogeneous grain structure and brittleness, the $\mathrm{Zn}$ can effectively modify the homogeneous grain structure into interfolded structure to enhances the bond reliability. In 3D IC structure, the reliability of complete IMC solder joints under thermal cycling loading, have been consider as an important research aspect, the finite element code can be used to calculate the stress-strain response and fatigue life of IMC solder joints. Tian ${ }^{[7]}$ researched the stress analysis and structure optimized of IMC joints in 3D 
package with finite element simulation, it is found that the resin thickness played the most important role but the resin hardness played the least important role in affecting the stress in the IMC joint.

In this paper, the IMCs and Sn-3.9Ag-0.6Cu solder joints have been considered in 3D IC, the effect of high temperature, low temperature, dwell time of thermal cyclic loading, and different IMCs on the solder joints reliability during thermal cyclic loading was studied using finite element method and Taguchi method. The results can provide an effective way to evaluate the reliability of IMC and $\mathrm{Sn}-3.9 \mathrm{Ag}-0.6 \mathrm{Cu}$ solder joints in 3D IC.

\section{FEM analysis}

In 3D ICs, the most significant elements of the enabling technology for handling and double-sided processing of extremely thin chips are the temporary bonding and debonding processes at lower temperature and higher throughput ${ }^{[8]}$. A common 3D device is shown in Fig.1, the two chips are bonded to form IMCs solder joints using TLP bonding, then the assembly is soldered on BT substrate with $\mathrm{Sn}-3.9 \mathrm{Ag}-0.6 \mathrm{Cu}$ alloy using reflow soldering bonding, meanwhile, during the second bonding, the first-level IMCs solder joints will not be molten and keep stable state. As the process of thermal cycling test is very time consuming and costly, finite element simulation is widely accepted in analyzing the mechanics and reliability of materials and structures like an electronic package especially during the design stage ${ }^{[9]}$. Finite element method has been proposed by many researchers to calculate the stress-strain and to predict the reliability of solder joints. The quarter symmetric FEA model of the 3D IC was utilized because of the symmetry both in the geometry, which can reduce the computational time. The quarter models have been utilized in BGA, CSP, WLCSP and QFP devices successfully in finite element simulation to calculate the fatigue life of solder joints under thermal cycle loading ${ }^{[10-12]}$.

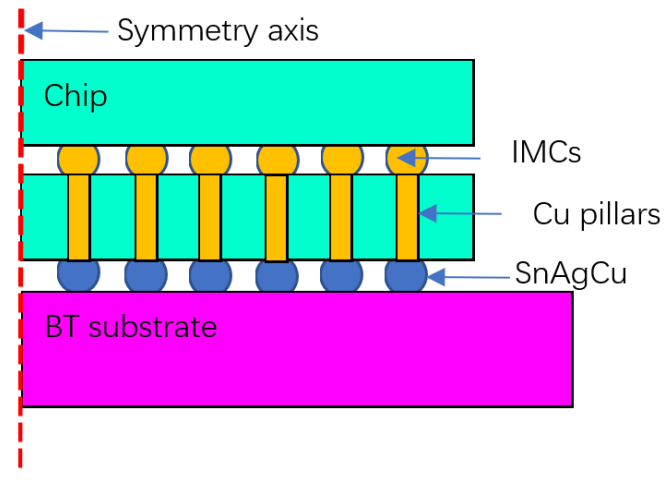

(a) Structure of 3D stacking

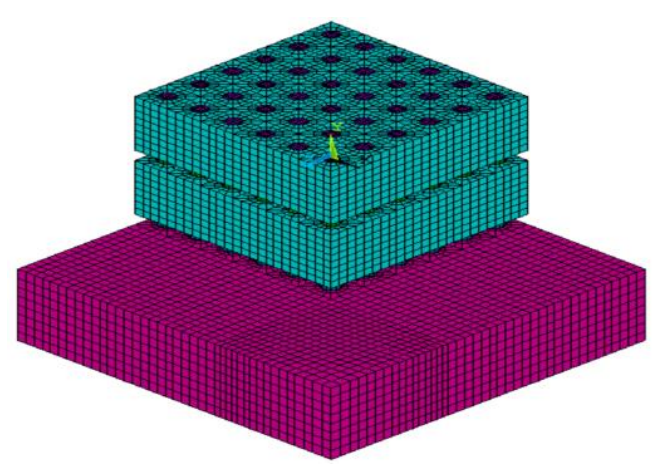

(b) $1 / 4$ finite element model

Fig.1 Finite element model of 3D IC

The finite element model of the 3D IC is shown in Fig.1 (b), the model consists of chips, IMCs/Sn-3.9Ag-0.6Cu solder joints, TSV $\mathrm{Cu}$ pillars, BT substrate and $\mathrm{Cu} / \mathrm{Ni}$ pads. SOLID186 with 20-node hexahedral element was selected to model the complex geometry to calculate the stress-strain response, and sweep mesh method was utilized in modeling. Since the focus is on the solder joints, finer meshes are used to model the 3D assembly, Fig. 2 shows the IMCs solder joints and $\mathrm{Sn}-3.9 \mathrm{Ag}-0.6 \mathrm{Cu}$ lead-free solder joints array. Meanwhile, the displacement boundary conditions are considered respectively, zero displacement constraints of vertical direction of the cross-area were applied to the cross-sections of the quarter model, namely all nodes on the symmetric surface $(X=0$, $\mathrm{Z}=0$ ) were fixed in the corresponding directions $(\mathrm{X}, \mathrm{Z})$, and the node at the origin $(\mathrm{X}=\mathrm{Y}=\mathrm{Z}=0)$ was 
constrained in all three directions.

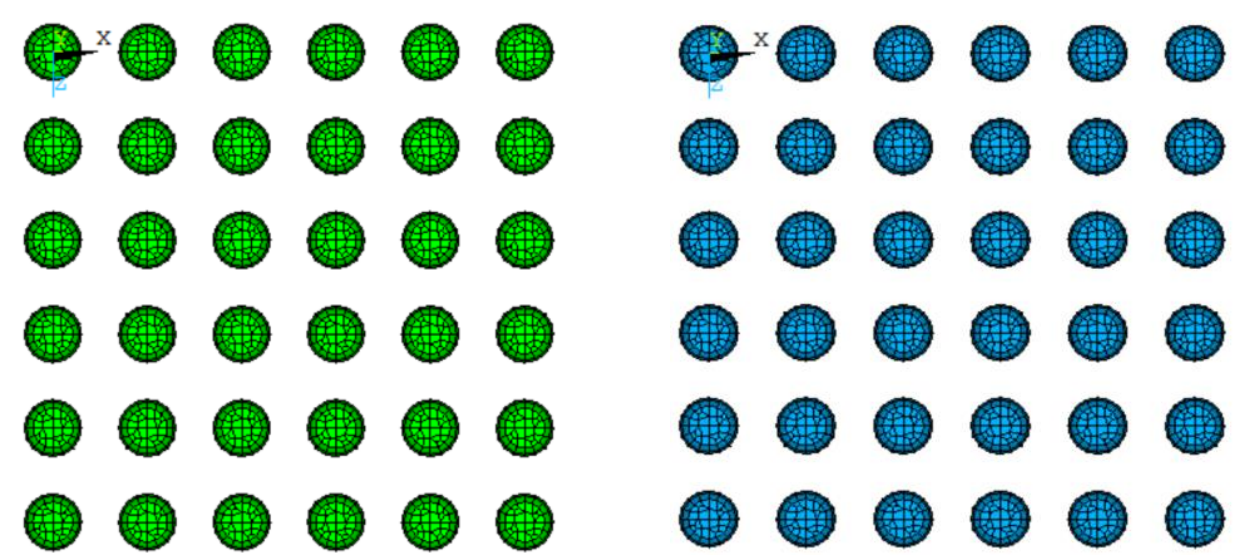

(a) IMCs solder joints array

(b) $\mathrm{Sn}-3.9 \mathrm{Ag}-0.6 \mathrm{Cu}$ solder joints array

Fig.2 Finite element model of solder joints array

Table 1 shows the material parameters of the chip, IMCs solder joint, $\mathrm{Ni} / \mathrm{Cu}$ pads and BT substrate in 3D assembly, these material parameters are assumed to be isotropic, linearly elastic and independent of temperature except for those of $\mathrm{Sn}-3.9 \mathrm{Ag}-0.6 \mathrm{Cu}$ solders ${ }^{[13]}$. It was well demonstrated that creep plays a very important role in deformation behavior of materials at homologous temperatures close to and above 0.5 if the loading rate is slow enough for creep deformations to occur $^{[14]}$. The Sn-3.9Ag-0.6Cu lead-free alloy is subjected to high homologous temperatures $(0.61)$ at room temperature. Therefore, the creep response may be considered as the main deformation of solder joints in service. In the finite element simulation, Garofalo-Arrhenius model was employed extensively to describe the steady-state creep of lead-free solder alloys ${ }^{[15]}$, Eq.(1) shows the creep model to calculate the creep behavior of $\mathrm{Sn}-3.9 \mathrm{Ag}-0.6 \mathrm{Cu}$ solders.

$$
\frac{d \gamma}{d t}=C\left(\frac{G}{T}\right)\left[\sinh \left(\omega \frac{\tau}{G}\right)\right]^{n} \exp \left(-\frac{Q}{R T}\right)
$$

where $\frac{d \gamma}{d t}$ is the creep shear strain rate, $G$ is the shear modulus, $T$ is the absolute temperature, $\omega$ is the stress level, $n$ is the stress exponent, $R$ is the gas constant, $C$ is the materials constant.

If the solder materials obey the von Mises criterion, the creep equation can be rearranged and expressed as ${ }^{[16]}$

$$
\dot{\varepsilon}=C_{1}\left[\sinh \left(C_{2} \sigma\right)\right]^{C_{3}} \exp \left(-\frac{C_{4}}{T}\right)
$$

where $\dot{\varepsilon}$ is the equivalent creep strain rate, $\sigma$ is the equivalent stress, $T$ is the absolute temperature. $C_{1}, C_{2}, C_{3}$ and $C_{4}$ are the materials constants, which are given in Table 2 for $\mathrm{SnAgCu}$ solder.

Table 1 Parameters of materials

\begin{tabular}{cccc}
\hline Materials & E/MPa & $\mu$ & $\mathrm{CTE} / \times 10^{-6} \mathrm{~K}^{-1}$ \\
\hline Sn-3.9Ag-0.6Cu & $43700-22.3 \mathrm{~T}$ & 0.4 & 20.9 \\
Chip & 163000 & 0.28 & 2.5 \\
$\mathrm{BT}$ & 26000 & 0.39 & 15 \\
$\mathrm{Cu}$ & 117000 & 0.23 & 16.6 \\
$\mathrm{Ni}$ & 207000 & 0.31 & 13.1 \\
\hline
\end{tabular}




\begin{tabular}{lcccc}
\hline $\mathrm{Cu}_{3} \mathrm{Sn}$ & 143000 & 0.3 & 18.2 \\
$\mathrm{Cu}_{6} \mathrm{Sn}_{5}$ & 124000 & 0.3 & 19.0 \\
$\mathrm{Ni}_{3} \mathrm{Sn}_{4}$ & 134000 & 0.33 & 13.7 \\
\hline \multicolumn{5}{c}{ Table 2 } \\
\hline Materials & $C_{1}$ & $C_{2}$ & $C_{3}$ & $C_{4}$ \\
\hline Sn-3.9Ag-0.6Cu & 441000 & $5 \mathrm{E}-9$ & 4.2 & 5412 \\
\hline
\end{tabular}

In evaluation of electronic device, accelerated thermal cycling tests are often utilized to speed up the thermal fatigue failure process assess the reliability of lead-free solder joints under cyclic temperature variation. According to the thermal cycling testing ${ }^{[17]}$, temperature from $218 \mathrm{~K}$ to $398 \mathrm{~K}$ was proposed to evaluate the reliability of IMCs and Sn-3.9Ag-0.6Cu lead-free solder joints in 3D IC, and duration of thermal cycle is $60 \mathrm{~min}$, including $15 \mathrm{~min}$ dwell at $218 \mathrm{~K}$ and $398 \mathrm{~K}$, which was shown in Fig.3. In order to analyze the parameters on the reliability of solder joints, high temperature, low temperature, dwell time of thermal cyclic loading are considered in finite element simulation, during the analyzing, the variation of high temperature, low temperature and dwell time are considered, the duration of thermal cycle still is $60 \mathrm{~min}$. In addition, it is assumed that no stress occurs at the initial temperature and at all nodes in the 3D assembly are loaded a uniform temperature distribution in the finite element simulation.

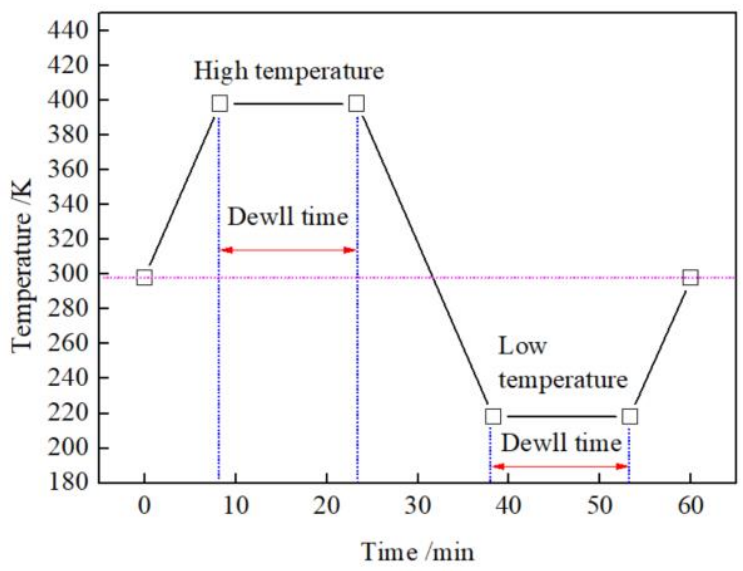

Fig.3 Temperature profile of thermal cyclic loading

\section{Results and discussion}

Fig.4 plots the von Mises stress and von Mises total mechanical strain of IMCs solder joints in 3D assembly, the maximum strain-strain is obtained in the second IMC solder joint of the chip oriented diagonally, which demonstrate that the diagonal position is more critical than the rectangular one. However, the stress-strain response of IMC solder joints is different with that of Sn-3.9Ag-0.6Cu solder joints. Fig.5 show the von Mises stress and von Mises total mechanical strain of $\mathrm{Sn}-3.9 \mathrm{Ag}-0.6 \mathrm{Cu}$ solder joints in the array, the findings show that the von Mises stress and von Mises total mechanical strain obviously with the increase of distance to neutral point, the maximum stress and strain occurred on the outer solder joint, and concentrated on the top surface of corner solder joint near the chip, the area may be the failure location of 3D assembly. In WLCSP device, $\mathrm{Wu}^{[18]}$ also found that the dangerous zone is the corner of the solder joint near the chip pad side, in addition, the crack extend in the location from experimental result, which demonstrates that the stress-strain response calculated can predict the failure location of solder joints. 


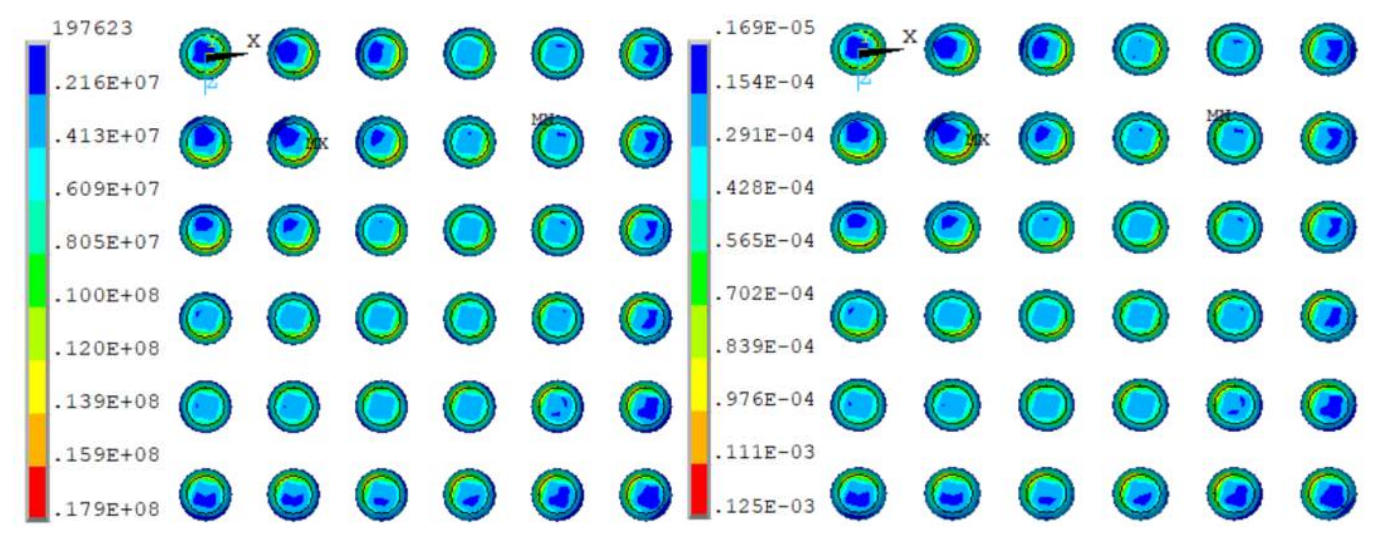

(a) Von Mises stress

(b) Von mises total mechanical strain

Fig.4 Stress-strain response of IMCs solder joints after thermal cyclic loading

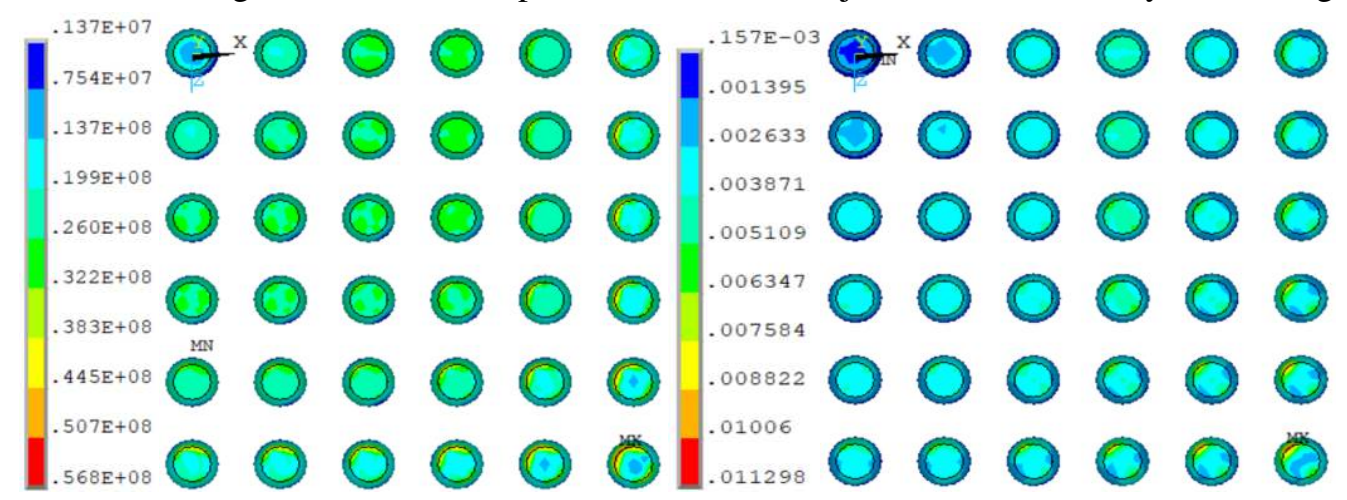

(a) Von Mises stress

(b) Von mises total mechanical strain

Fig.5 Stress-strain response of Sn-3.9Ag-0.6Cu solder joints after thermal cyclic loading

Fig. 6 shows the deformed shapes $(500 \mathrm{X})$ of the $3 \mathrm{D}$ assembly after three thermal cycles, the maximum displacement can be found in the Sn-3.9Ag-0.6Cu solder joint array, it can be found with the increasing of the distance with the center solder joints, the displacement increases obviously, the displacement mainly concentrates at corner solder joints in the 3D assembly, due to the mismatch of thermal expansion coefficient between chip and substrate, the solder joints are subjected to very lager deformation. In WLCSP device, $\operatorname{Lau}^{[19]}$ found the same phenomena in WLCSP device with $\mathrm{Sn}-2 \mathrm{Ag}-36 \mathrm{~Pb}$ and $\mathrm{Sn}-3.5 \mathrm{Ag}$ solders under thermal cycle loading.

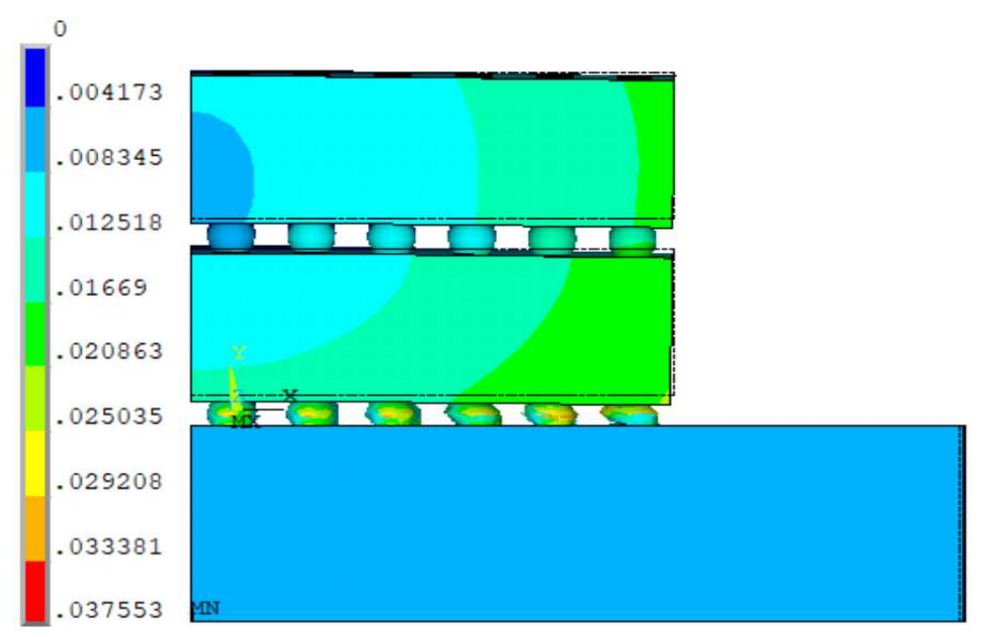

Fig.6 Displacement vector sum $(500 \times)$ 
The Taguchi method is widely used to analyze the factor level combination and to assess effect factor, so the method is selected in our research to determine the effect of different control factors on the reliability of solder joints in the 3D assembly. In 1980, Taguchi's introduction of robust design to several major American industries, including AT \& T, Ford and Xerox, resulted in significant quality improvements in product and manufacturing process design ${ }^{[20]}$. For Taguchi method, the orthogonal array $(\mathrm{OA})$ and signal-to-noise $(\mathrm{S} / \mathrm{N})$ ratios are the main instruments for economically conducting and analyzing an experiment ${ }^{[21]}$. The idea of orthogonal arrays is to get the statistic information and robust process conditions during shorter time by using fewer analyses. With the consideration of control factors and their levels, the $\mathrm{L}_{9}\left(3^{4}\right)$ orthogonal array is to be used in the optimized experiment to minimize the creep strain $\Delta \varepsilon$. The robust design (or quality) characteristics can be classified into three different types: 1) Nominal-the best, 2) smaller-the-better, and 3) larger-the-better ${ }^{[22]}$. In 3D assembly, the design of the chip stacked structure, the stress-strain of the solder joints has to be minimized, the smaller-the-better criteria is suitable to describe the experimental results. The signal-to-noise $(S / N)$ objective function for the quality characteristic of smaller-the-better type was computed as shown in Eq.(3):

$$
S / N=-10 \log \left(\frac{\sum_{i=1}^{r} y_{i}^{2}}{r}\right)
$$

where $r$ is the total number of measurements, $y_{i}$ is the $i$ th measurement data, and $S / N$ is the signal-to-noise ration in decibel.

In the finite element simulation, the $r=1$ and $\mathrm{y}=\Delta \varepsilon$, so the $\frac{\sum_{i=1}^{r} y_{i}^{2}}{r}=\Delta \varepsilon^{2}$, therefore, the Eq.(3) can be transforms to

$$
S / N=-10 \log \left(\Delta \varepsilon^{2}\right)
$$

The four selected control factors and their levels applied in this study are tabulated in Table 3. these control factors contain high temperature, low temperature, dwell time of thermal cyclic loading, and different IMCs. And the control factors all show three levels. $\mathrm{Cu}_{6} \mathrm{Sn}_{5}, \mathrm{Cu}_{3} \mathrm{Sn}$ and $\mathrm{Ni}_{3} \mathrm{Sn}_{4} \mathrm{IMCs}$ were selected in this paper, these IMCs show higher melting temperature than Sn-based alloys.

Table 3 Control factors and levels

\begin{tabular}{|l|l|l|l|l|}
\hline Control factors & & Level 1 & Level 2 & Level 3 \\
\hline A & IMC & $\mathrm{Cu}_{6} \mathrm{Sn}_{5}$ & $\mathrm{Cu}_{3} \mathrm{Sn}$ & $\mathrm{N}_{3} \mathrm{Sn}_{4}$ \\
\hline B & High Temperature & $423 \mathrm{~K}$ & $398 \mathrm{~K}$ & $373 \mathrm{~K}$ \\
\hline C & Low Temperature & $233 \mathrm{~K}$ & $218 \mathrm{~K}$ & $213 \mathrm{~K}$ \\
\hline D & Dwell time & $15 \mathrm{~min}$ & $12.5 \mathrm{~min}$ & $10 \mathrm{~min}$ \\
\hline
\end{tabular}

The Taguchi method can effectively find out the optimal condition of production to ensure the consistency and get the best quality control with the lowest $\cos ^{[23]}$. In order to obtain the optimal parameters of the 3D assembly, the main experiment is carried out to analyze the control factors and levels within Taguchi method. Table 4 shows the simulated creep strain $(\Delta \varepsilon)$ and the $\mathrm{S} / \mathrm{N}$ ration for each experiment cells on the $\mathrm{L}_{9}\left(3^{4}\right)$ orthogonal array. It is found that with the variation of high temperature, low temperature, dwell time of thermal cyclic loading, and different IMCs, the creep strain $(\Delta \varepsilon)$ and $S / N$ ratio change significantly. The smaller value of creep strain $(\Delta \varepsilon)$ demonstrated 
that the more reliability of $\mathrm{Sn}-3.9 \mathrm{Ag}-0.6 \mathrm{Cu}$ solder joints in 3D assembly. And the evaluation of $\mathrm{Sn}-3.9 \mathrm{Ag}-0.6 \mathrm{Cu}$ solder joints is based on the quality factor $\Delta \varepsilon$.

Table 4 Main experiment

\begin{tabular}{|l|l|l|l|l|l|l|}
\hline \multirow{2}{*}{ EXP. } & \multicolumn{4}{|l}{ Factor and level } & \multicolumn{2}{l|}{ Quality } \\
\cline { 2 - 7 } & $\mathrm{A}$ & $\mathrm{B}$ & $\mathrm{C}$ & $\mathrm{D}$ & $\Delta \varepsilon$ & $S / N$ \\
\hline 1 & 1 & 1 & 1 & 1 & 0.0842156667 & 21.49 \\
\hline 2 & 1 & 2 & 2 & 2 & 0.0705263333 & 23.03 \\
\hline 3 & 1 & 3 & 3 & 3 & 0.0557870000 & 25.07 \\
\hline 4 & 2 & 1 & 2 & 3 & 0.0833843333 & 21.58 \\
\hline 5 & 2 & 2 & 3 & 1 & 0.0706106667 & 23.02 \\
\hline 6 & 2 & 3 & 1 & 2 & 0.0562143333 & 25.00 \\
\hline 7 & 3 & 1 & 3 & 2 & 0.0838226667 & 21.53 \\
\hline 8 & 3 & 2 & 1 & 3 & 0.0695220000 & 23.16 \\
\hline 9 & 3 & 3 & 2 & 1 & 0.0570686667 & 24.87 \\
\hline Average & & & & 23.19 \\
\hline
\end{tabular}

Fig.7 shows the S/N ratio response diagram of the four control factors, magnitudes of the control factors response and ranks are summarized in Table 5. According to the $\mathrm{S} / \mathrm{N}$ response diagram, the greater is the $\mathrm{S} / \mathrm{N}$ ration, the smaller is the variation of equivalent creep strain, the effect of four factors is different, the contribution degree of the four factors is Factor B (High Temperature)> Factor $\mathrm{D}$ (Dwell time) $>$ Factor $\mathrm{C}($ Low Temperature) $>$ Factor $\mathrm{A}(\mathrm{IMCs})$, the most important factor is the high temperature, which demonstrates that the reliability of the $\mathrm{Sn}-\mathrm{Ag}-\mathrm{Cu}$ solder joints in 3D assembly can be influenced mainly by high temperature of thermal cycles loading, other three parameters have small impact on the reliability, especially for IMCs, we should enhance the reliability of $\mathrm{Sn}-\mathrm{Ag}-\mathrm{Cu}$ solder joints based on the optimal design. And the optimal parameters match is $\mathrm{A} 1 / 2 \mathrm{~B} 3 \mathrm{C} 1 \mathrm{D} 3$, namely the optimal design in the 3D assembly has the combination of the $\mathrm{Cu}_{6} \mathrm{Sn}_{5} / \mathrm{Cu}_{3} \mathrm{Sn}$, high temperature at $373 \mathrm{~K}$, low temperature at $233 \mathrm{~K}$, Dwell time at $10 \mathrm{~min}$. Moreover, it is imperative to illustrate that when the levels are varied, the optimal set of the control factors and rank then change obviously. The effect deviation of factor (IMCs) on S/N repose is very small and negligible.

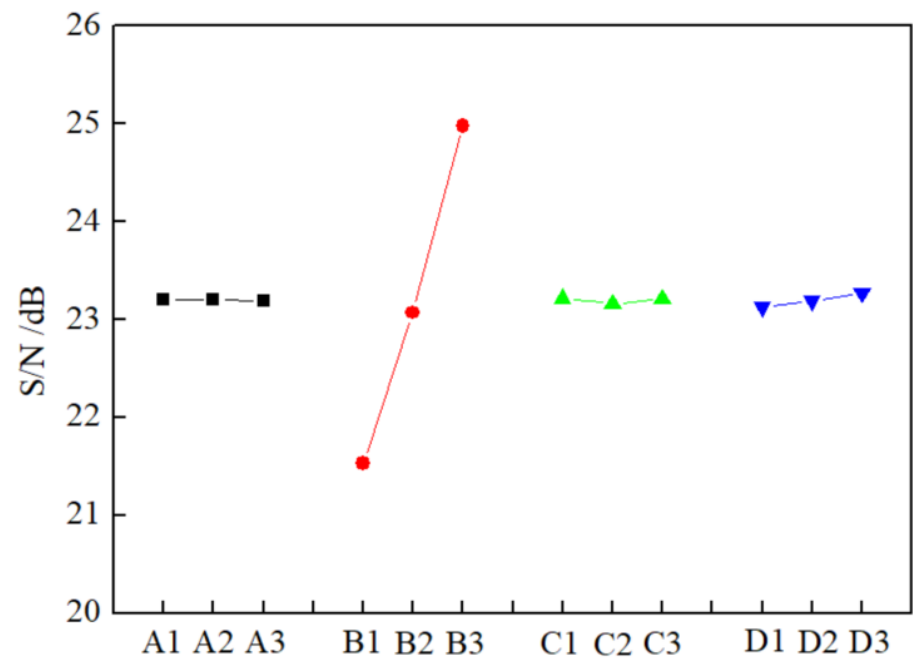

Fig.7 S/N response diagram 
Table $5 \mathrm{~S} / \mathrm{N}$ response and rank

\begin{tabular}{|c|c|c|c|c|}
\hline & \multicolumn{4}{|c|}{ Factor and level } \\
\hline & $\mathrm{A}$ & $\mathrm{B}$ & $\mathrm{C}$ & $\mathrm{D}$ \\
\hline Level 1 & 23.20 & 21.53 & 23.22 & 23.13 \\
\hline Level 2 & 23.20 & 23.07 & 23.16 & 23.19 \\
\hline Level 3 & 23.19 & 24.98 & 23.21 & 23.27 \\
\hline Effect & 0.01 & 3.45 & 0.06 & 0.14 \\
\hline Rank & 4 & 1 & 3 & 2 \\
\hline
\end{tabular}

For the two different temperature profiles of thermal cycle loading, the durations of thermal cycle are all 60min, only high temperature, low temperature, dwell time are different, based on the finite element simulation combined with Taguchi method, only high temperature can affect the reliability of solder joints, when high temperature $(T)$ changes obviously, the ramp rate $(\mathrm{r}=T / s)$ will also vary. Therefore, in this paper, high temperature and ramp rate have same effect, only high temperature was selected as a analyzed parameter.

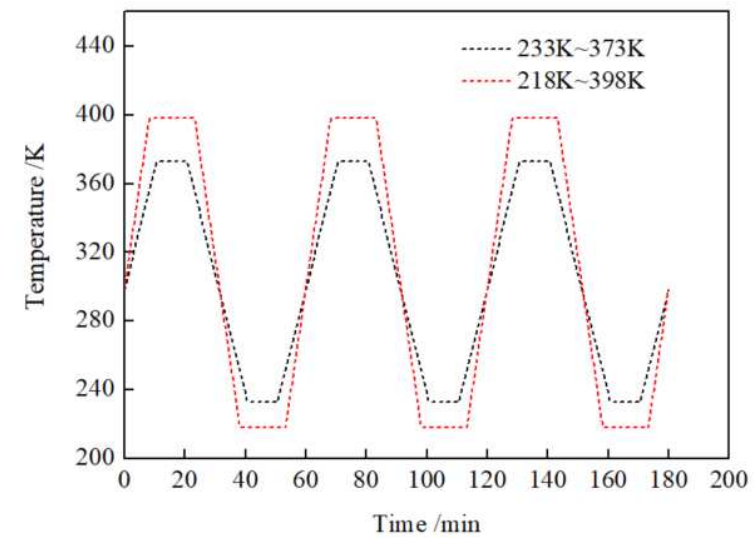

Fig.8 Two different temperature profiles of thermal cyclic loading

Fig. 9 shows the history of von Mises stress and equivalent creep strain history at the corner Sn-3.9Ag-0.6Cu solder joints of the 3D assembly, respectively. It is found that the von Mises stress and equivalent creep strain history of $\mathrm{Sn}-3.9 \mathrm{Ag}-0.6 \mathrm{Cu}$ solder joints under $218 \mathrm{~K} \sim 398 \mathrm{~K}$ loadding is higher than that of solder joints under $233 \mathrm{~K} \sim 373 \mathrm{~K}$ loading, which demonstrates that the decrease of high temperature can decrease the von Mises stress and equivalent creep strain history under thermal cycling. Moreover, low stress can be found in the von Mises stress curve during the high temperature stage of the thermal cyclic loading, while high stress appears in the low temperature stage. Due to creep effect stress relaxation happens both at the high and low temperature dwell stage. For the second and third thermal cycle, the $\mathrm{Sn}-3.9 \mathrm{Ag}-0.6 \mathrm{Cu}$ solder joints reach a stabilized cyclic pattern where the highest stress is experienced at the beginning of the low temperature dwell and the lowest stress at the end of the high temperature dwell because of the viscous behavior of the solder joints. Meanwhile it is observed that both equivalent creep strain increase as the temperature cycle proceeds, and the thermally induced cyclic creep deformation tends to accumulate as the number of the thermal cycle increase. The creep strain of Sn-3.9Ag-0.6Cu solder joints under $218 \mathrm{~K} \sim 398 \mathrm{~K}$ loading higher than that of solder joints under $233 \mathrm{~K} \sim 373 \mathrm{~K}$ loading, which can be attributed to the enhancement of creep strain with the increase of high temperature. Moreover, the high temperature increases, the ramp rate will increase significantly, the equivalent creep strain will be boosted. 


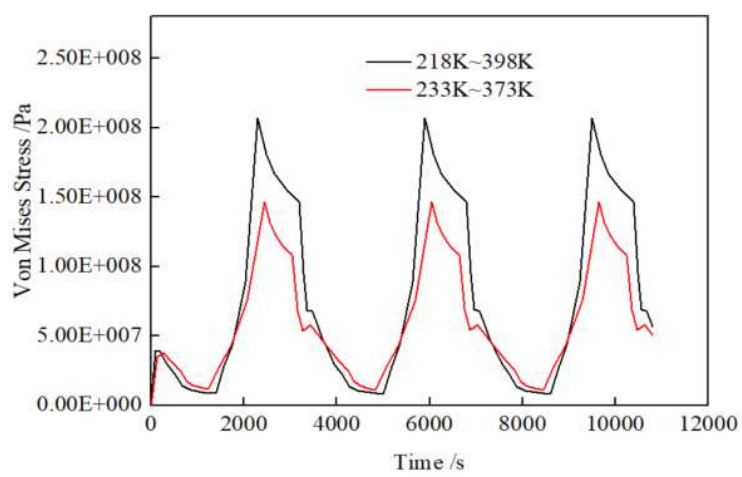

(a)Von Mises stress

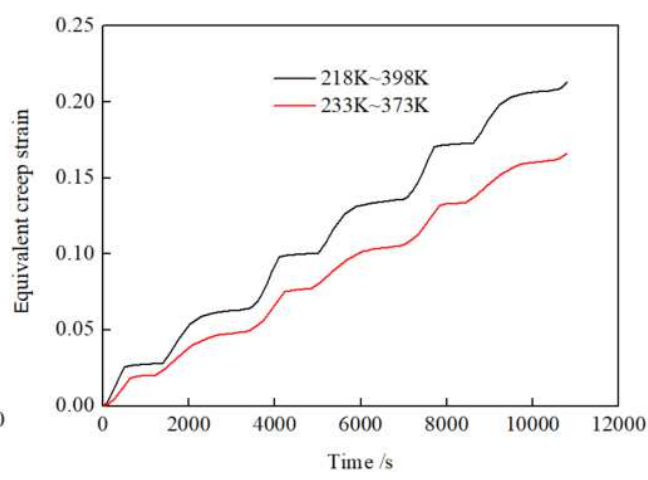

(b)Equivalent creep strain

Fig.9 Stress-strain response of $\mathrm{Sn}-\mathrm{Ag}-\mathrm{Cu}$ solder joints

With the finite element simulated data, combing the fatigue life equations of the solder joints, the Sn-3.9Ag-0.6Cu solder joints in 3D assembly can be calculated effectively. A number of fatigue life prediction models have been proposed in the literature, and the prediction equations based on accumulated creep strain show obvious superiority. Syed ${ }^{[24]}$ suggested that creep is the primary damage mechanism for Sn-Ag-Cu solder during thermal cycling and can be used to simulate the material's behavior, so the creep deformation can be considered in the life prediction model. Fatigue life prediction equation of $\mathrm{Sn} 3.9 \mathrm{Ag}-0.6 \mathrm{Cu}$ solder joints based on accumulated creep strain is as follows ${ }^{[25]}$ :

$$
N_{f}=(0.0405 \Delta \varepsilon)^{-1}
$$

Where $N_{f}$ is the number of cycles to failure, $\Delta \varepsilon$ is the accumulated creep strain per cycle.

The fatigue lives of $\mathrm{Sn}-3.9 \mathrm{Ag}-0.6 \mathrm{Cu}$ under $218 \mathrm{~K} \sim 398 \mathrm{~K}$ and $233 \mathrm{~K} \sim 373 \mathrm{~K}$ loading in the 3D assembly based on the creep strain are 347.4 cycles and 445.5 cycles, which demonstrates that the increase of high temperature of the thermal cycles loading can increase the equivalent creep strain and reduce the fatigue life of $\mathrm{Sn}-3.9 \mathrm{Ag}-0.6 \mathrm{Cu}$ solder joints in $3 \mathrm{D}$ assembly. Fig.10 shows the crack of solder joint in experiments (380cycles, $218 \mathrm{~K} 398 \mathrm{~K}$ ), the results have a good agreement with the simulated result predicts the failure location. Due to the mismatch of thermal expansion coefficient between chip and substrate, the solder joint is subjected to creep strain, when the accumulated creep strain reaches a critical value, the crack may initial and propagate.

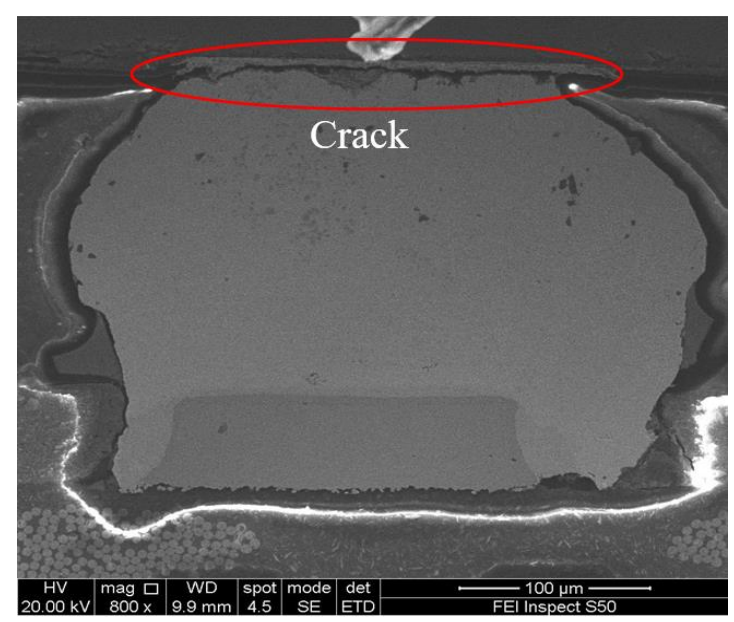

Fig.10 The crack of corner solder joints 


\section{Conclusion}

The stress-strain response of IMCs $\left(\mathrm{Ni}_{3} \mathrm{Sn}_{4}, \mathrm{Cu}_{3} \mathrm{Sn}, \mathrm{Cu}_{6} \mathrm{Sn}_{5}\right)$ solder joints and $\mathrm{Sn}-3.9 \mathrm{Ag} 0.6 \mathrm{Cu}$ solder joints in 3D assembly was investigated using finite element simulation and Taguchi method. It is found that the high temperature is most important factor among all the four control factors (high temperature, low temperature, dwell time of thermal cyclic loading, and different IMCs), and the stress-strain response and fatigue life of the $\mathrm{Sn}-3.9 \mathrm{Ag}-0.6 \mathrm{Cu}$ solder joints in $3 \mathrm{D}$ assembly can be influenced mainly by high temperature of thermal cycles loading, other three parameters have small impact on the reliability, especially for IMCs.

\section{Availability of data and materials}

All data and materials have been presented in this manuscript.

\section{Competing interests}

The authors declare that they have no competing interests.

\section{Funding}

The present work was carried out with the support of State Key Lab of Advanced Welding and Joining, Harbin Institute of Technology (AWJ-19Z04); Major State Research Development Program of China (2019YFF0217400); the Central Plains Science and Technology Innovation Leading Talents Program (ZYQR20180030).

\section{Authors' contributions}

Zhang Liang analyzed and interpreted the patient data in this paper, and was a major contributor in writing the manuscript. Zhong Su-juan was responsible for revising the grammar of the manuscript. All authors read and approved the final manuscript.

\section{Acknowledgments (Not applicable)}

\section{References}

[1]Zhang L, Liu Z Q, Chen S W, Wang Y D, Long W M, Guo Y H, Wang S Q, Ye G, Liu W Y. Materials, Processing and reliability of low temperature bonding in 3D chip stacking[J]. Journal of Alloys and Compounds, 2018, 750:980-995.

[2]Ko C T, Chen K N. Low temperature bonding technology for 3D integration[J]. Microelectronics Reliability, 2012, 52:302-311.

[3]Tu K N, Hsiao H Y, Chen C. Transition from flip chip solder joint to 3D IC microbump: its effect on microstructure anisotropy[J]. Microelectronics Reliability, 2013, 53:2-6.

[4]Talebanpour B, Huang Z, Chen Z, Dutta I. Effect of joint scale and processing on the fracture of Sn-3Ag-0.5Cu solder joints: Application to micro-bumps in 3D packages[J]. Journal of Electronics Materials, 2016, 45(1):57-68.

[5]Chu K, Sohn Y, Moon C. A comparative study of $\mathrm{Cu} / \mathrm{Sn} / \mathrm{Cu}$ and $\mathrm{Ni} / \mathrm{Sn} / \mathrm{Ni}$ solder joints for low 
temperature stable transient liquid phase bonding[J]. Scripta Materialia, 2015, 109:113-117.

[6]Chen W Y, Song R W, Duh J G. Grain structure modification of Cu-Sn IMCs by applying Cu-Zn UBM on transient liquid-phase bonding in novel 3D-IC technologies[J]. Intermetallics, 2017, $85: 170-175$.

[7]Tian Y H, Wang N, Yang D S, Wang C Q. Stress analysis and structure optimization of IMC joints in 3D package[J]. Transactions of the China Welding Institution, 2012, 33(8):17-20.

[8]Annuar s, Mahmoodian R, Hamdi M, Tu K N. Intermetallic compounds in 3D integrated circuits technology: a brief review[J]. Science and Technology of Advanced Materials, 2017, 18(1):693-703.

[9]Otiaba K C, Bhatti R S, Ekere N N, Mallik S, Ekpu M. Finite element analysis of the effect of silver content for $\mathrm{Sn}-\mathrm{Ag}-\mathrm{Cu}$ alloy compositions on thermal cycling reliability of solder die attach[J]. Engineering Failure Analysis, 2013, 28:192-207.

[10]Lall P, Islam M N, Singh N, Suhling J C, Darveaux R. Model for BGA and CSP reliability in automotive underhood applications[J]. IEEE Transactions on Components and Packaging Technologies, 2004, 27(3):585-593.

[11] Zhang L, Sun L, Han L, Guo Y H. Reliability of lead-free solder joints in WLCSP device with finite element simulation and Taguchi method[J]. International Journal of Nonlinear Sciences and Numerical Simulation, 2014, 15(6):405-410.

[12] Zhang L, Han J G, He C W, Guo Y H. Reliability behavior of lead-free soldered joints in electronic components[J]. Journal of Materials Science: Materials in Electronics, 2013,24(1):172-190.

[13]Samavatian M, Samavation V, Moayeri M, Babaei H. Effect of stress triaxiality on damage evolution of porous solder joints in IGBT discretes[J]. Journal of Manufacturing Processes, 2018, 32:57-64.

[14]Li X Y, Wang Z S. Thermo-fatigue life evaluation of $\mathrm{SnAgCu}$ solder joints in flip chip assemblies[J]. Journal of Materials Processing Technology, 2007, 183(1):6-12.

[15]Zarmai M T, Ekere N N, Oduoza C F, Amalu E H. Evaluation of thermo-mechanical damage and fatigue life of solar cell solder interconnections[J]. Robotics and Computer-Integrated Manufacturing, 2017, 47:37-43.

[16] Zhang L, Xue S B, Gao L L, Zeng G, Chen Y, Yu S L, Sheng Z. Creep behavior of SnAgCu solders with rare earth Ce doping[J]. Transactions of Nonferrous Metals Society of China, 2010, 20(3): 412-417.

[17]Zhang L, Han J G, Guo Y H, He C W. Effect of rare earth Ce on the fatigue life of SnAgCu solder joints in WLCSP device using FEM and experiments[J]. Materials Science and Engineering A, 2014, 597:219-224.

[18]Wu K C, Lin S Y, Hung T Y, Chiang K N. Reliability assessment of packaging solder joints under different thermal cycle loading rates[J]. IEEE Transactions on Device and Materials Reliability, 2015, 15(3):437-442.

[19]Lau J H, Lee S W R. Modeling and analysis of 96.5Sn-3.5Ag- lead-free solder joints of wafer level chip scale package on buildup microvia printed circuit board[J]. IEEE Transactions on Electronics Packaging Manufacturing, 2002, 25(1):51-58.

[20] Li M H C, Hong S M. Optimal parameter design for chip-on-film technology using the Taguchi method[J]. The International Journal of Advanced Manufacturing Technology, 2005, 25(1-2):145-153.

[21]Tsai T N, Liukkonen M. Robust parameter design for the micro-BGA stencil printing process 
using a fuzzy logic-based Taguchi method[J]. Applied Soft Computing, 2016, 48:124-136.

[22]Mertol A. Application of the Taguchi method on the robust design of molded 225 plastic ball grid array packages[J]. IEEE Transactions on Components, Packaging, and Manufacturing Technology, 1995, 18(4):734-743.

[23]Jong W R, Chen S C, Tsai H C, Chiu C C, Chang H T. The geometrical effects of bumps on the fatigue life of flip-chip packages by Taguchi method[J]. Journal of Reinforced Plastics and Composites, 2006, 25(1):99-114.

[24]Syed A. Accumulated creep strain and energy density based thermal fatigue life prediction models for $\mathrm{SnAgCu}$ solder joints[C]. $54^{\text {th }}$ Electronic Components and Technology Conference, Las Vegas, NV, USA, 2004.

[25]Zhang L, Han J G, Guo Y H, He C W, Lai Z M, Wang H W. Fatigue life prediction of Sn-3.9Ag-0.6Cu soldered joints in WLCSP device[J]. Transactions of the China Welding Institution, 2012, 33(3):97-100. 


\section{Figures}

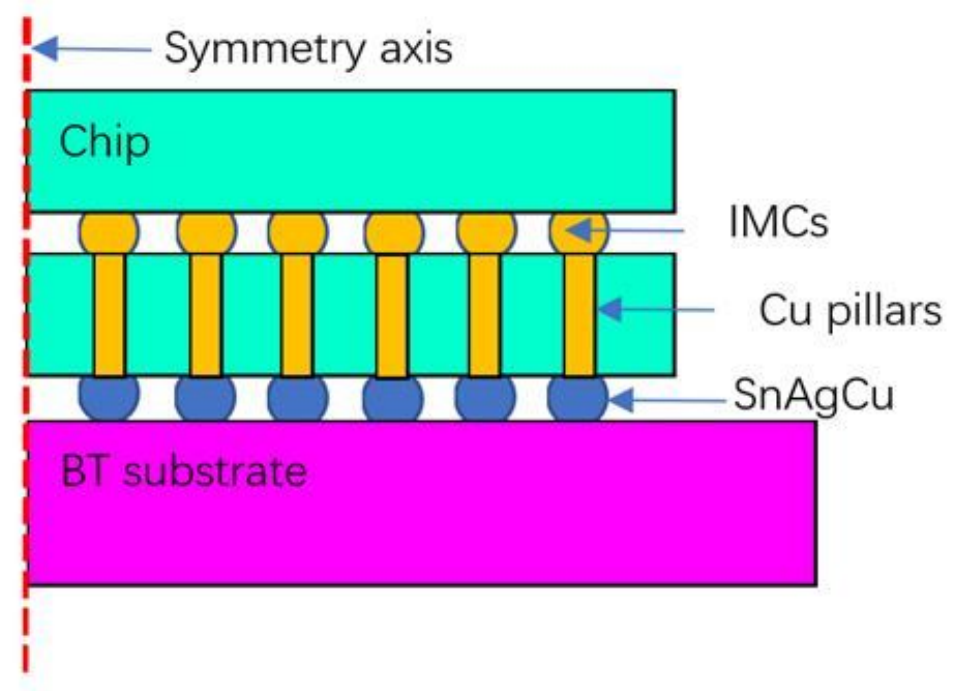

(a) Structure of $3 \mathrm{D}$ stacking

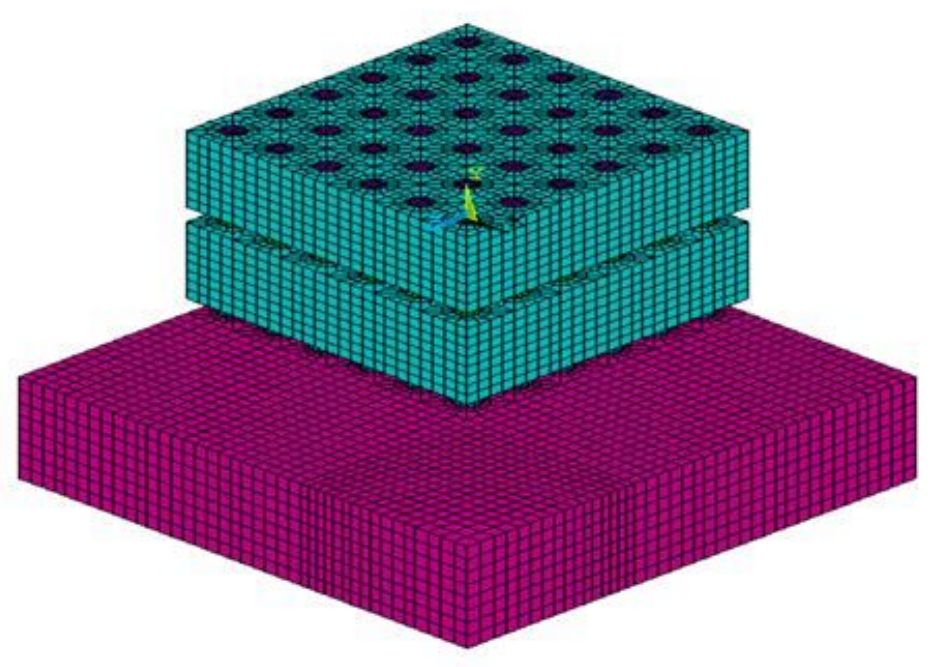

(b) 1/4 finite element model

Figure 1

Finite element model of 3D IC

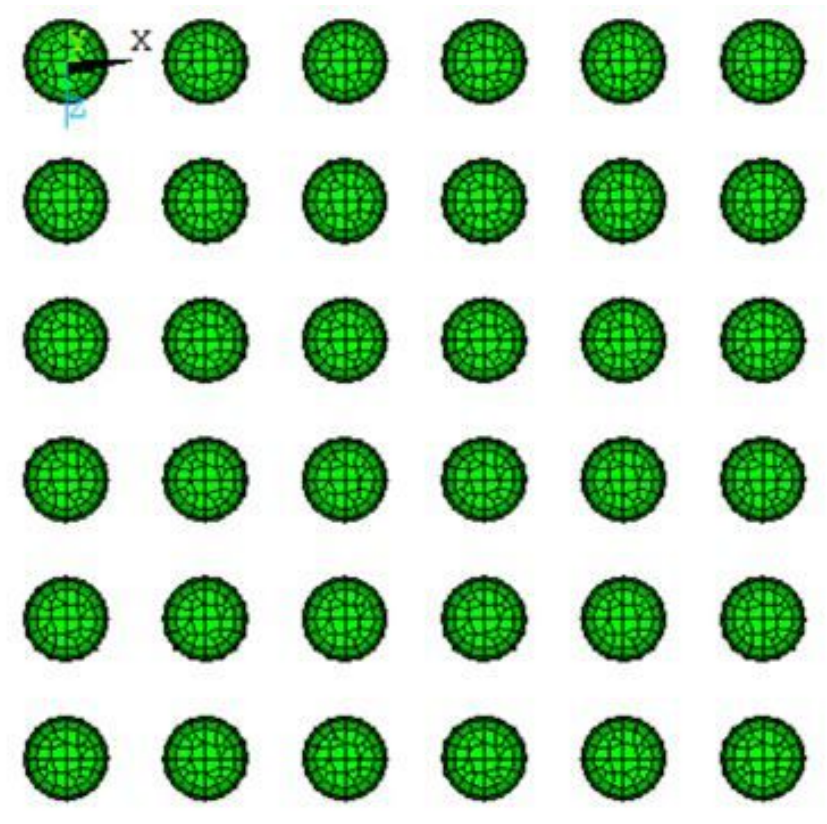

(a) IMCs solder joints array
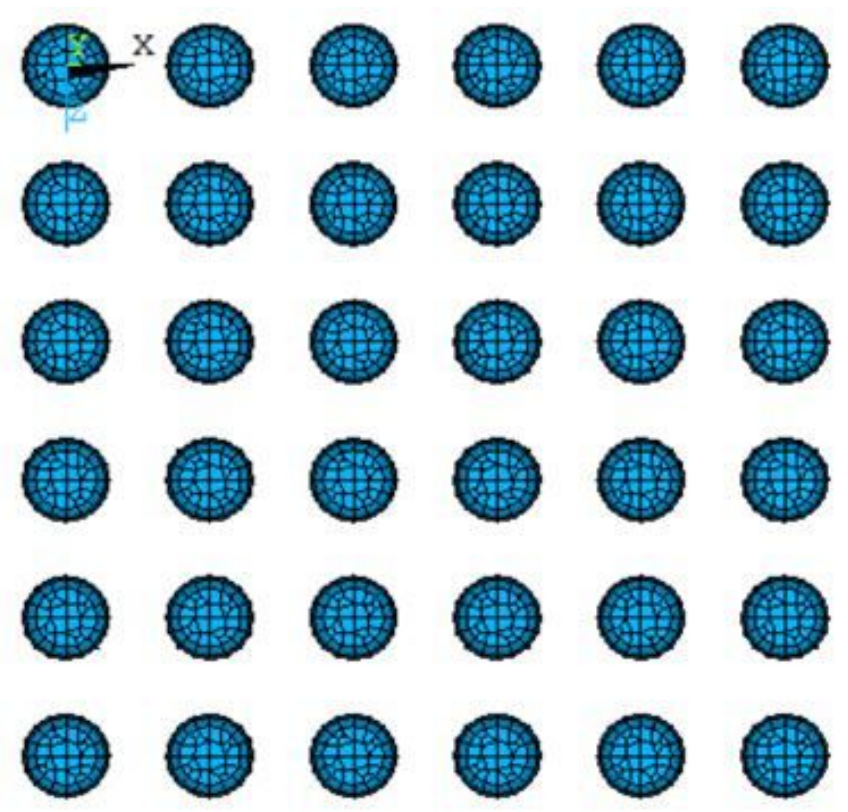

(b) $\mathrm{Sn}-3.9 \mathrm{Ag}-0.6 \mathrm{Cu}$ solder joints array

Figure 2

Finite element model of solder joints array 


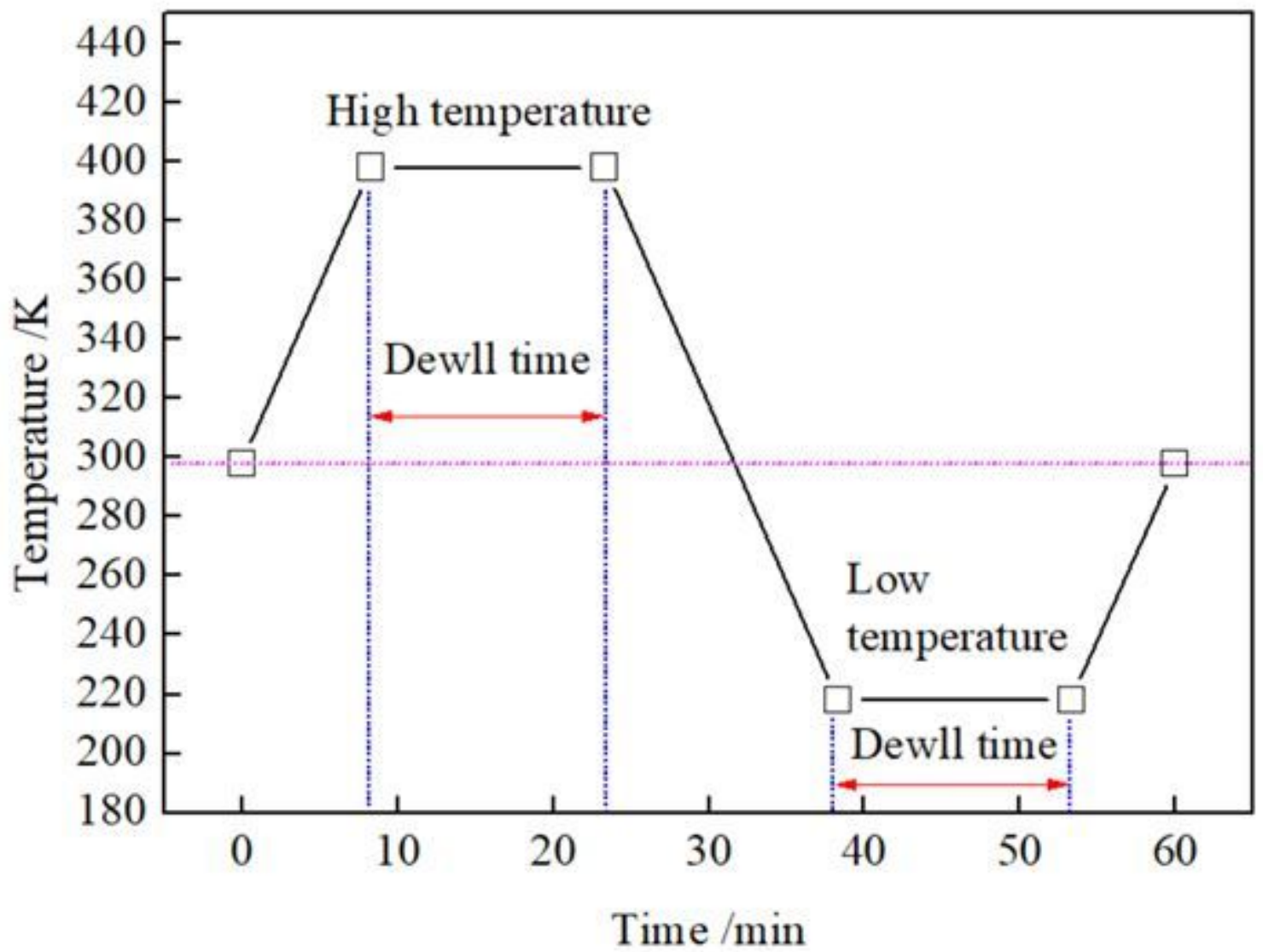

Figure 3

Temperature profile of thermal cyclic loading

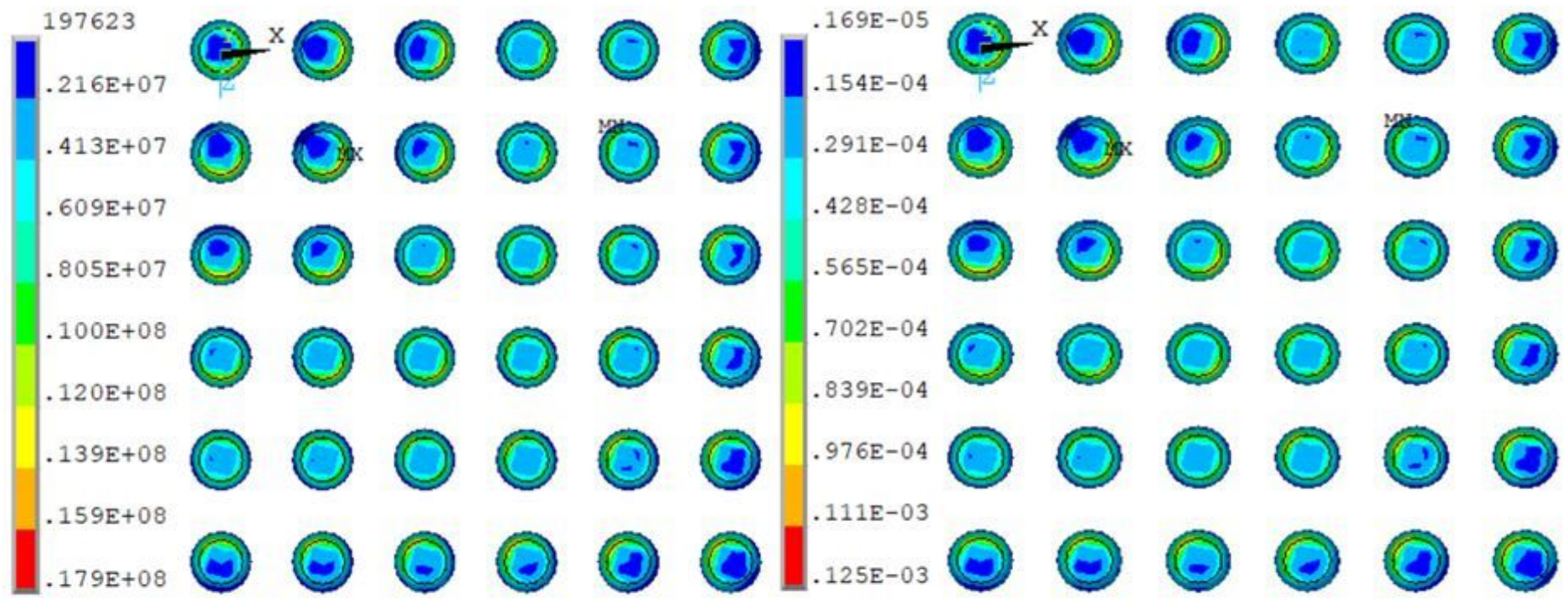

(a) Von Mises stress

(b) Von mises total mechanical strain

Figure 4

Stress-strain response of IMCs solder joints after thermal cyclic loading 


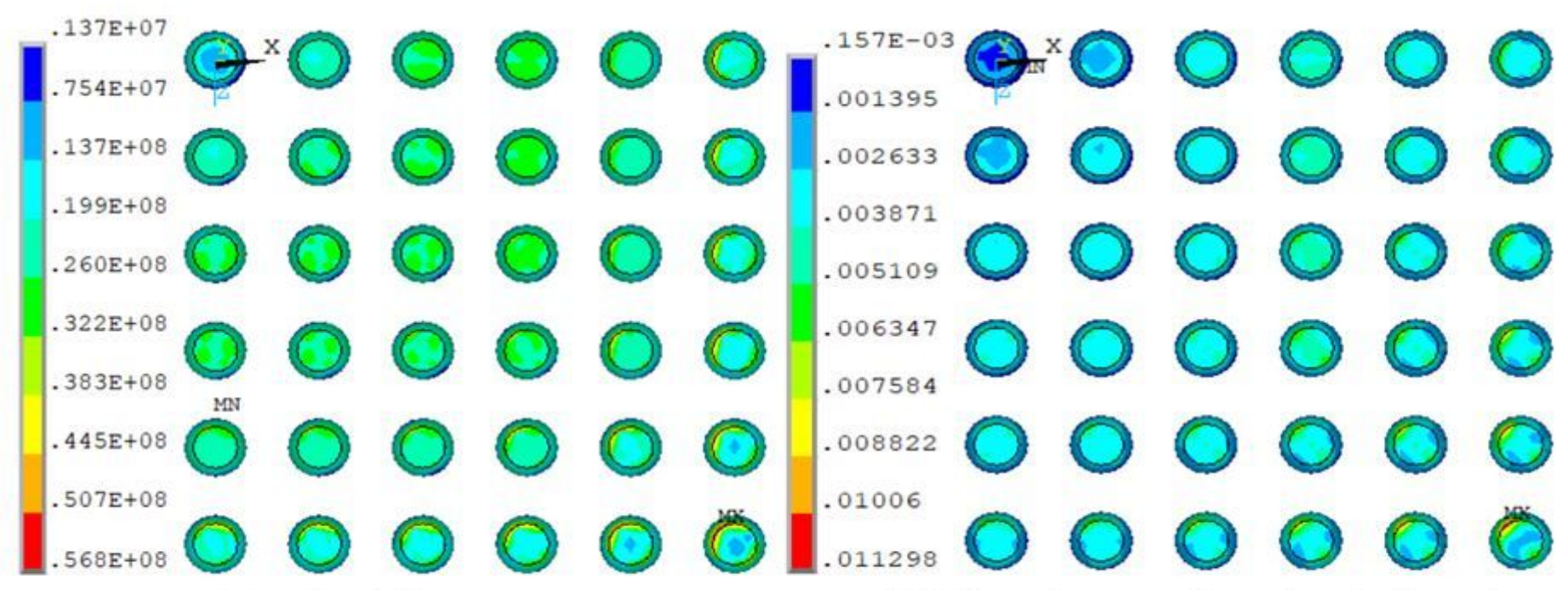

(a) Von Mises stress

(b) Von mises total mechanical strain

\section{Figure 5}

Stress-strain response of Sn-3.9Ag-0.6Cu solder joints after thermal cyclic loading

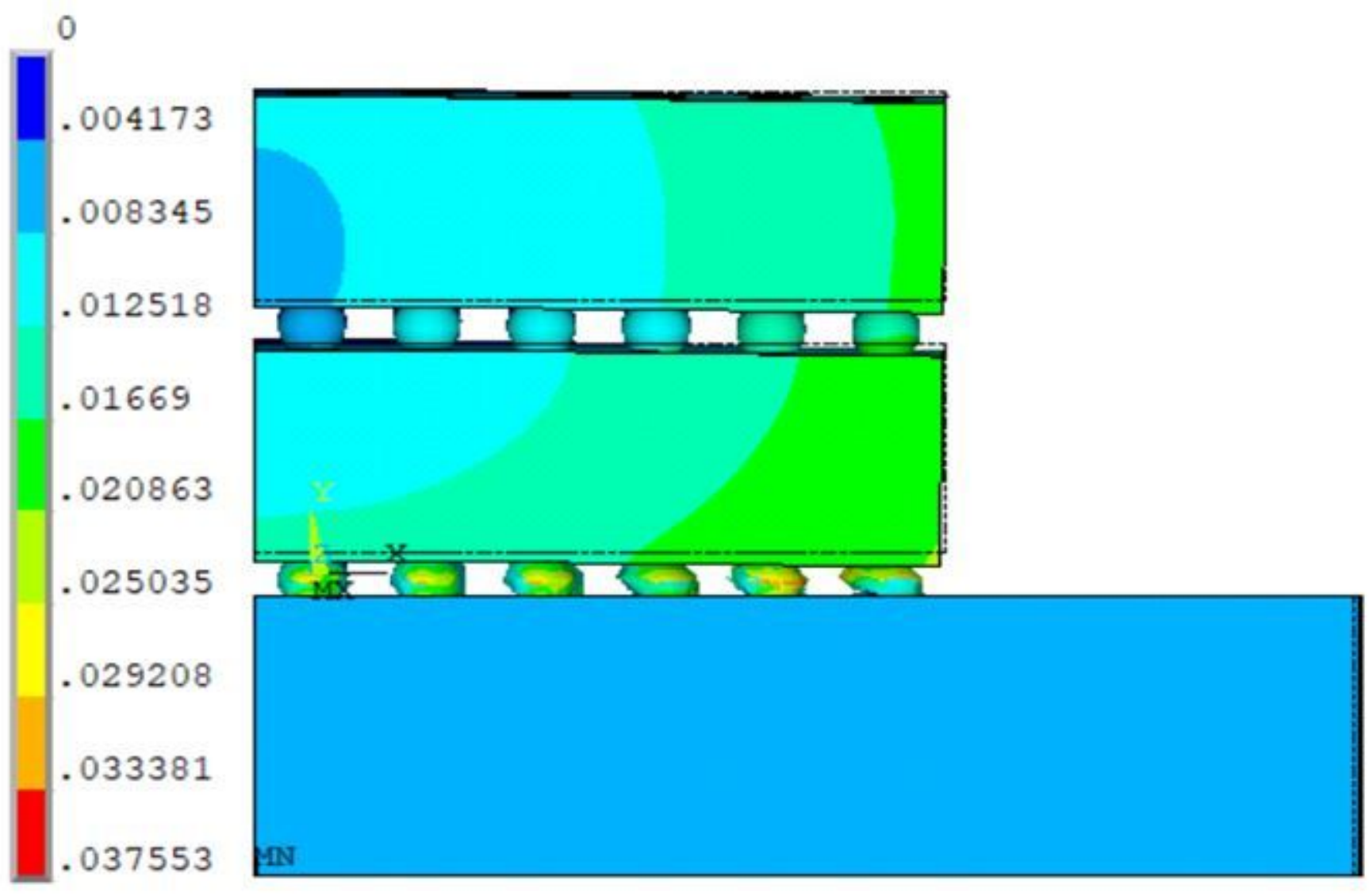

Figure 6

Displacement vector sum (500x) 


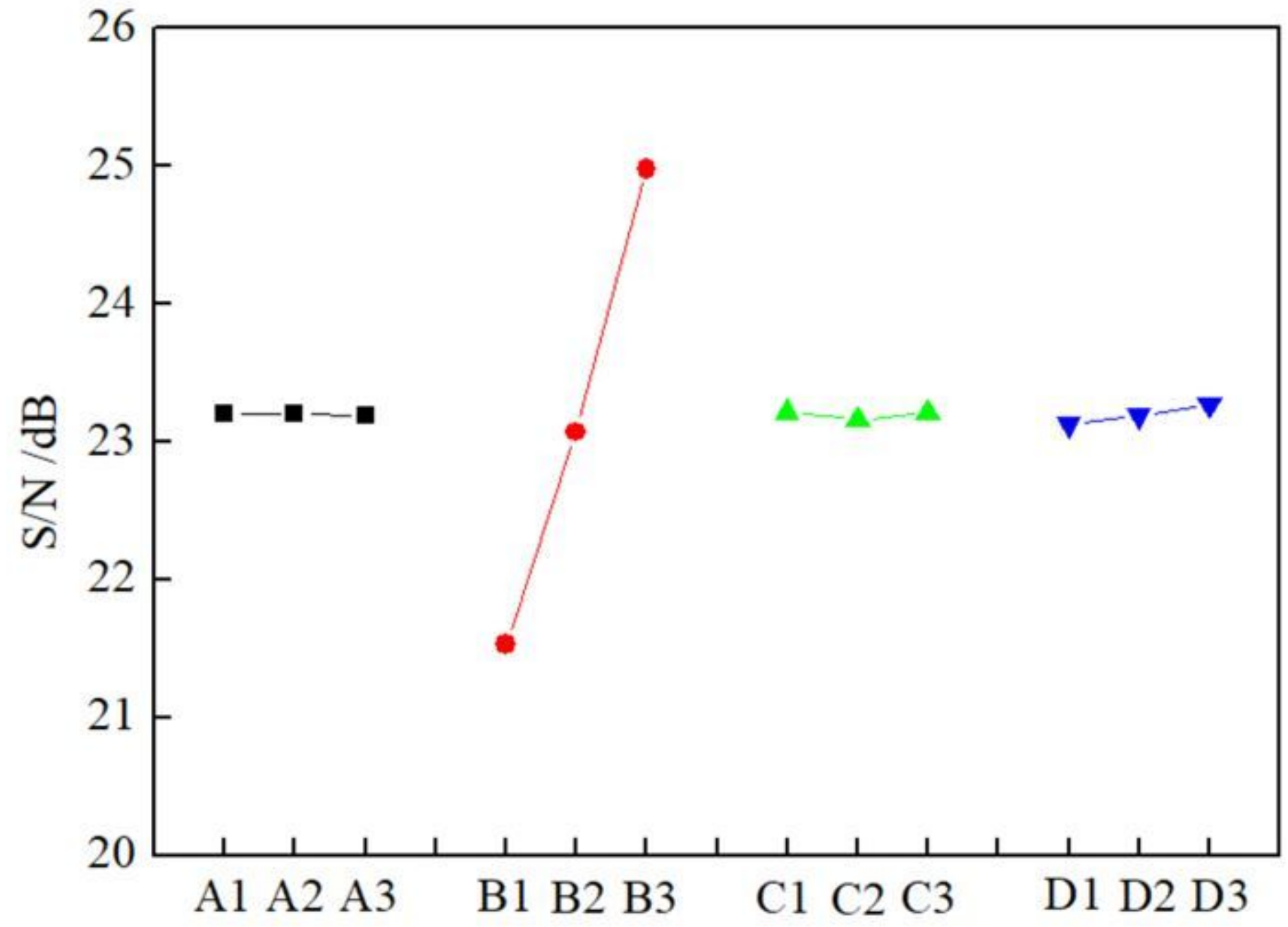

Figure 7

$\mathrm{S} / \mathrm{N}$ response diagram 


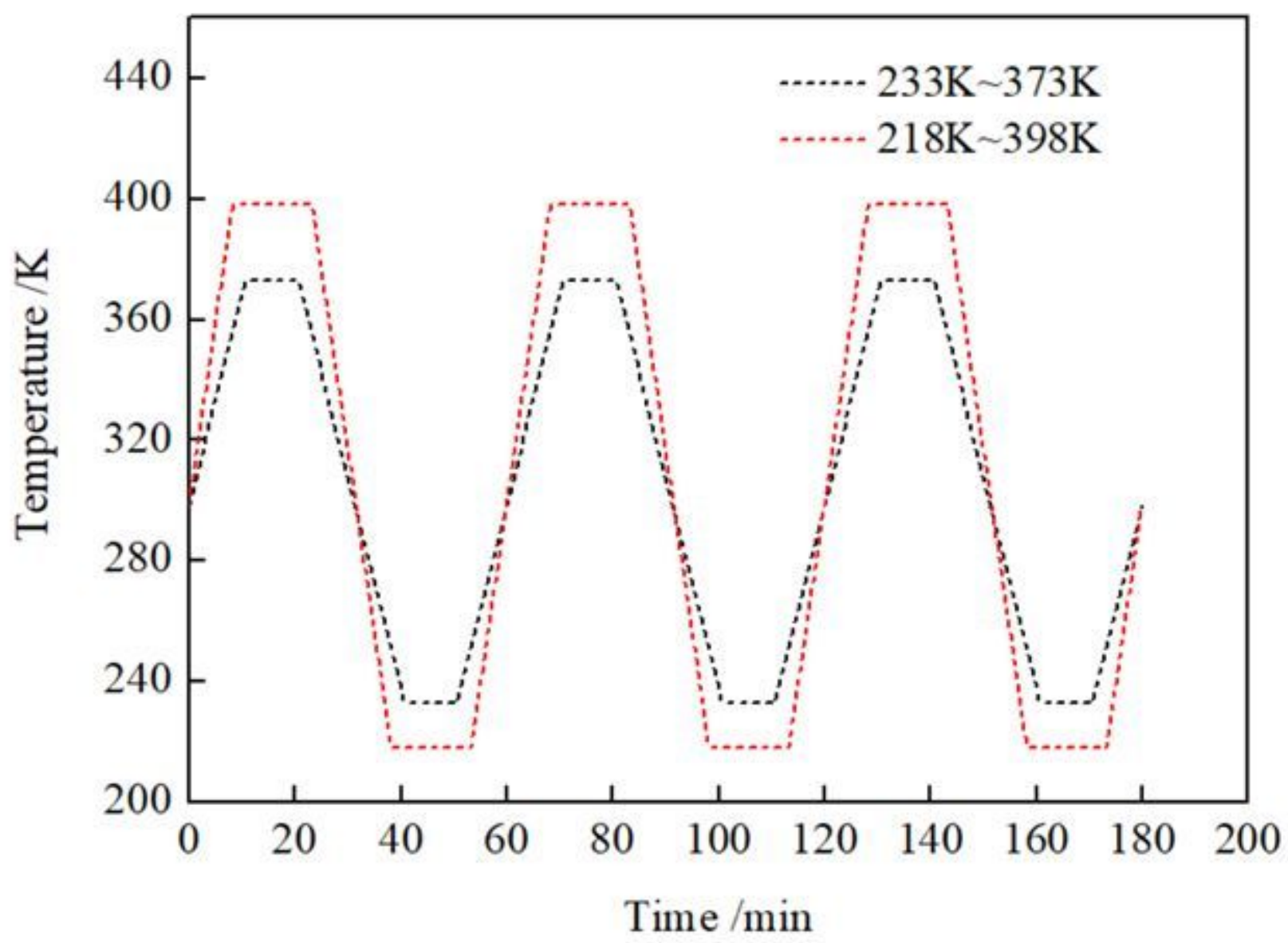

Figure 8

Two different temperature profiles of thermal cyclic loading

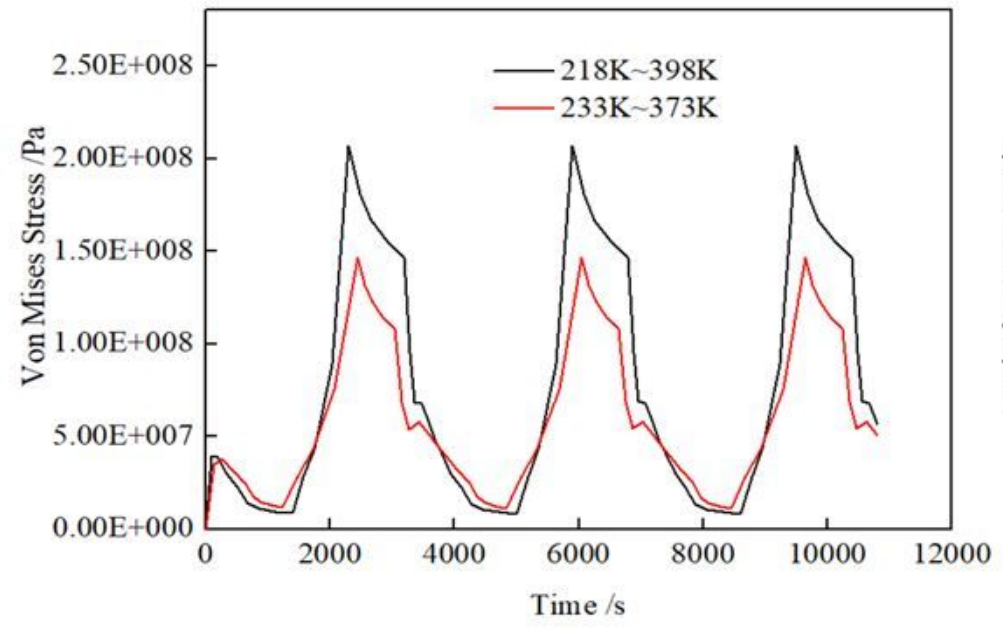

(a)Von Mises stress

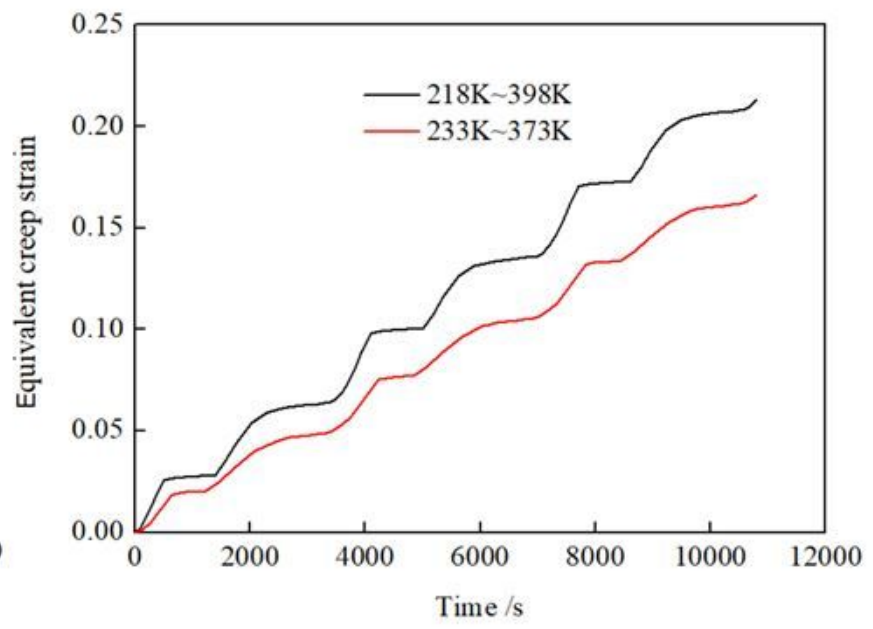

(b)Equivalent creep strain

\section{Figure 9}




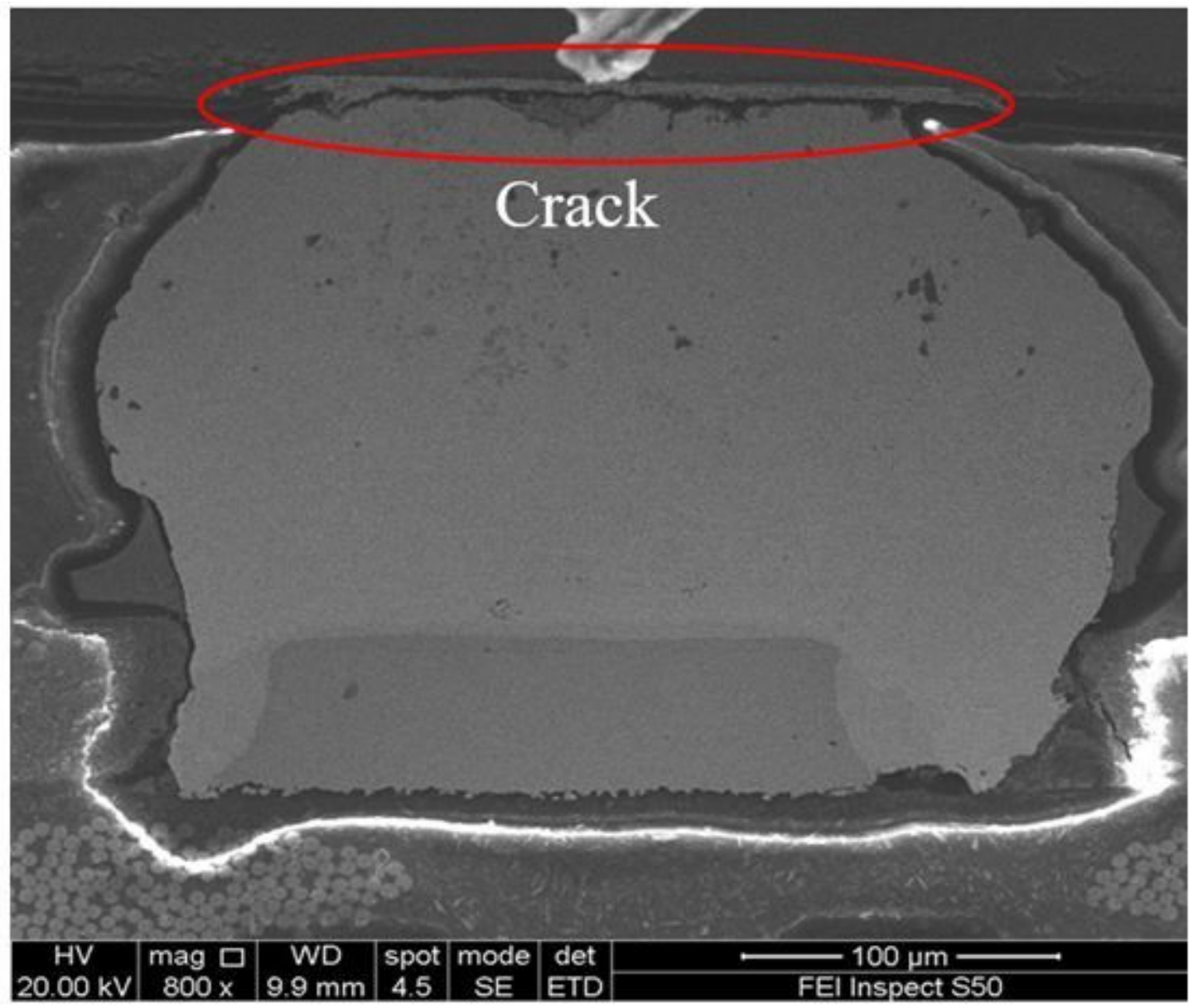

Figure 10

The crack of corner solder joints 